\title{
Supporting Urban Consolidation Centres with Urban Freight Transport Policies: A Comparative Study of Scotland and Sweden
}

\author{
Emine Zehra Akgün ${ }^{1}$, Jason Monios ${ }^{2}$, Achille Fonzone ${ }^{1}$ \\ 1) Transport Research Institute, Edinburgh Napier University, United Kingdom \\ Email: E.Akgun@napier.ac.uk, A.Fonzone@napier.ac.uk
}

2) Kedge Business School, Domaine de Luminy, Rue Antoine Bourdelle, Marseille, France. Email: Jason.Monios@kedgebs.com

This is the pre- published version of the text. The final published paper can be found at:

Emine Zehra Akgün, Jason Monios \& Achille Fonzone (2019) Supporting urban consolidation centres with urban freight transport policies: a comparative study of Scotland and Sweden, International Journal of Logistics Research and Applications.

DOI: $10.1080 / 13675567.2019 .1679743$

\begin{abstract}
This study investigates how supportive urban freight transport (UFT) policies work in conjunction with stakeholder collaboration to support public-led urban consolidation centre (UCC) developments. The methodology was a multiple case study approach, comparing cases in Sweden and Scotland, two countries that are more/less advanced in their approach to UFT policy. The key finding reveals that while UFT policies such as time window restrictions can support successful UCCs, they cannot be considered in isolation from the collaborative UFT policy setting established by the local authority. A successful development also requires a commitment to financially support the UCC over at least the medium term, allowing time for the system to mature and collaborative service offerings to be developed. The findings of this study can be used by local authorities to establish a supportive UFT policy setting, as well as specifically designing policy packages in conjunction with UCC business models.
\end{abstract}

Keywords: urban freight transport; logistics; urban consolidation centre; policy; collaboration 


\section{INTRODUCTION}

Urban freight transport (UFT) is an essential function for cities, yet, despite their low share in total traffic, freight vehicles are one of the major sources of air pollution, congestion and road casualties in cities (Dablanc 2007). Local authorities seek to address these problems by applying various policy measures, yet there have been only a few studies analysing the role of local authorities in UFT. Lindholm (2013) found that UFT is infrequently included in local transport planning due to its complex nature and it is more often considered the business of private companies. Lindholm (2013) also argued that local authorities need a better understanding of policy measures, evaluation, transferability and stakeholder involvement. Ballantyne, Lindholm and Whiteing (2013) emphasized the importance of working with a wider range of stakeholders if local authorities want to become better at planning and executing UFT in the context of their local transport strategies. Yet public authorities often lack sufficient resources to focus attention on the dynamics of freight transport, including the requirements and viewpoints of all stakeholders (Stathopoulos, Valeri, and Marcucci 2012). Lindholm and Blinge (2014) advised that local authorities need to develop a certain degree of knowledge concerning UFT and related interest groups; otherwise, local transport policies may become counterproductive. They further advised that local authorities need to consider technological and behavioural policy measures together if they want to regulate urban traffic in the most efficient ways. Akgün et al. (2019) found that most cities tend to choose their UFT policy measures from a pool of common measures (primarily access restrictions such as time windows and weight restrictions), but without monitored targets that determine whether or not they are achieving objectives. Kiba-Janiak (2017) investigated the level of maturity in planning and implementing UFT strategies in twelve European capital cities, finding that cities with written UFT plans have the widest range of UFT projects. The most popular policy measures found were low cost policy measures such as access restrictions. However, initiatives requiring long term partnerships such as urban consolidation centres (UCC) were less popular. De Marco, Mangano, and Zenezini (2018) analysed 70 European cities that have been piloting or implementing UFT policy measures. Use of low emission vehicles, UCCs and Low Emission Zones were the most common, implemented in more than $50 \%$ of the case cities.

UCCs are logistics facilities that consolidate deliveries into fewer (preferably low emission) vehicles. Allen et al. (2012) and Allen et al. (2014) listed different types of UCCs in three major categories; they are (a) the facilities that serve all or part of an urban area, (b) the facilities that serve large sites with a single landlord such as shopping centres or airports, and (c) facilities that serve construction sites. Type A and Type B UCCs are associated with retail products, office products and food supplies, while type $\mathrm{C}$ are designed for handling building materials. Type A UCCs are designed 
to serve areas where there are narrow streets, historic layouts and/or lack of loading and unloading bays in urban areas. These UCCs are often initiated by local authorities and they may receive various forms of public support (e.g. financial, direct or indirect regulatory support) (Allen et al. 2014; Lebeau et al. 2017). On the other hand, type B and type C UCCs are usually initiated by private organizations such as owners/developers of shopping malls and constructions contractors. They aim to tackle issues related to on-site storage, retailing space and planning permissions for construction projects.

This study focuses on type A UCCs, which serve all or part of an urban area, usually associated with retail products. These UCCs are usually initiated by local authorities to mitigate problems concerning air quality, congestion and road safety (Browne et al. 2005; Allen et al. 2014), but their implementation requires collaboration between various stakeholders with different objectives and priorities (Yang and Moodie 2011), which can be summarised as three main groups: local authorities, logistics service providers (LSPs) and retailers (Harrington et al. 2016). For example, local authorities want both to support existing businesses and to attract new businesses while at the same time protecting the environment and quality of life for citizens, while private freight operators and retailers focus on cost reduction and the reliability and flexibility of their delivery operations. In order to protect these priorities, they are reluctant to use UCCs. Several authors have found that the major problem with UCC projects is that their inability to attract sufficient users limits their financial viability; many have failed either after public subsidies ended or have been discontinued after feasibility studies (Quak and Tavasszy 2011; Allen et al. 2012; Kin et al. 2016; Johansson and Björklund 2017; Paddeu 2017).

While this growing body of literature reveals that the challenges of UCCs are fairly well established, only a small amount of work has begun to consider how local authorities can implement accompanying policy measures in order to encourage the use of UCCs. A small group of studies has identified the potential measures, the most popular including direct financial support, tax incentives, favourable measures to UCC operators (e.g. off-hour deliveries), exemptions from access restrictions (e.g. time and weight restrictions), and receiver led consolidation in combination with delivery servicing plans (Panero, Shin, and Lopez 2011; Ville, Gonzalez-Feliu, and Dablanc 2013; HolguínVeras et al. 2016; Marcucci and Gatta 2017; Lebeau et al. 2017). Recognising the small amount of literature on UFT policy and local authorities, as well as the importance of the public-private collaborative context of UFT, this paper aims to explore not only which policy measures are most successful but particularly the interrelation between the supportive measures and the UCC development process. Thus, the research question for this study is: How do supportive UFT policies work in conjunction with stakeholder collaboration to support successful public-led UCC developments? 
The literature review analyses previous research on both supportive UFT policies and stakeholder collaboration, as well as the challenges and service profile of UCCs, in order to provide an analytical framework for analysing the entire collaborative context of UCC developments. The methodology is based on analysis of two case studies from Sweden and Scotland. The Swedish case represents an active UCC serving retailers in Gothenburg. The Scottish case was an unsuccessful attempted UCC project, which aimed at serving retailers in Perth and Dundee. Including a failed case is less common in case study research which tends to focus on best practice, thus this comparison can enable us to view both sides of the situation.

\section{LITERATURE REVIEW}

\section{Challenges faced by UCC developments}

The biggest challenge facing UCCs is their financially viability (Kin et al. 2016; Janjevic and Ndiaye 2017). Over the years, freight operators have become particularly successful at consolidating freight during the earlier phases of their supply chains. Therefore, it is less attractive when UCCs are added as an extra link in supply chains, leading to increased set-up and operating costs. As consolidation operations usually take place before freight vehicles travel to city centres, using UCCs may not obtain any operational and economic benefits for freight operators (Browne et al. 2005). However, Browne, Allen, and Leonardi (2011) identified that it is still possible to achieve other benefits for highly consolidated goods, such as improvements in air quality with the help of electric vehicles and decreasing the total distance travelled by conventional vehicles. Kin et al. (2016) argued that the feasibility of UCCs depends on availability of a critical mass and the conditions in areas that deliveries take place such as restrictions or congested traffic.

Cost is one of the most crucial factors to decide whether customers are willing to use a UCC or not. Janjevic and Ndiaye (2017) argue that a UCC should be able to decrease delivery costs through providing gains in terms of distance and time. They identified the key factors influencing the cost attractiveness of UCCs as the distance to UCCs and enabling off-hour deliveries, factor and pricing of services, the density of the delivery zone and the size of cities, and the mode of management. According to Aastrup, Gammelgaard, and Prockl (2012), customers favour less frequent deliveries as a result of the agglomeration of parcels.

Another problem that UCCs face is the challenge in establishing a business model that can balance economic, environmental and operational requirements for different stakeholders (Quak, Balm, and Posthumus 2014; Nordtømme, Bjerkan, and Sund 2015; Björklund, Abrahamsson, and 
Johansson 2017). The lack of an appropriate business model can also lead to contractual and organizational problems and loss of direct contact with suppliers and customers (Browne et al. 2005: Allen et al. 2012). Lagorio, Pinto, and Golini (2016) identified particular reasons why UCC projects fail at different stages of their implementation, such as discontinued public funds, location (if it is too far from delivery points) and lack of systems that enable tracking and tracing. The authors also identified that potential stakeholders hesitate to participate in UCC projects due to maintenance of customer service levels, security of goods, lack of involvement of stakeholders in decision-making processes and potential conflicts with local authorities.

\section{Stakeholder collaboration in UCC developments}

The involvement of multiple stakeholders is one of the most critical characteristics of UCCs. Consortia that aim to initiate UCC projects are characterized by complex relationships between public and private actors over a period of time. Harrington et al. (2016) identified key considerations and interdependencies to be considered during the initial development of UCCs. The set of stakeholders consists of three main actors: freight operators/logistics companies, local businesses and public authorities. Their study shows that each individual stakeholder seeks for his or her individual objectives and they need to have a set of common objectives if all stakeholders want to collaborate. In addition, the timing of stakeholder involvement is crucial, and they should be involved as early as possible in the development process (Macharis and Verlinde 2012).

Logistics service and transport providers mainly focus on generating revenues, developing inhouse skills, enhancing their brand reputation and using innovative tools to develop their businesses. Many international corporates such as DHL, Amazon and UPS focus on developing innovative solutions that will enable them to develop new ways of providing logistics activities in local settings such as using low emission vehicles, initiating micro consolidation centres or enabling multimodal transport (Quak 2011; Ducret 2014). As the final customer of the deliveries from the UCCs, retailers focus on the factors concerning the quality of the service that they obtain from their transport suppliers. Therefore, they focus on familiarity, reliability and flexibility in delivery operation, insurance, parcel aggregation and personal and friendly contact with transport companies (Harrington et al. 2016).

Public authorities want both to support existing businesses and to attract new businesses to be located in their cities, which contribute to economic growth (Olsson and Woxenius 2014; Harrington et al. 2016). At the same time, both national and local authorities have a responsibility to protect public health and wellbeing and quality of life in cities, which means they need strategies to reduce emissions and congestion. This is why UCCs and the use of low emission vehicles are starting to be adopted in 
some cities (Browne, Allen, and Leonardi 2011; Paddeu 2017). Many local authorities in Europe have already included the promotion and the use of low emission vehicles in their planning for both passenger and freight transport (Muñuzuri et al. 2005; Dablanc 2007).

All the aforementioned stakeholders can develop a common agenda and strive for the same goals while considering their individual objectives. In this way, stakeholders can agree upon how they will initiate UCCs, share cost and risk and develop ideas concerning what other policies and initiatives they need to increase the effectiveness of UCCs. Van Duin et al. (2018) identified four key elements to stakeholder collaboration in UFT, which will be used in the analytical framework: the need for public action, awareness of barriers, building on large players and empowering small players.

\section{Use of supporting policies for UCC developments}

Local authorities are beginning to combine the use of UCCs with other type of policies that offer exemptions and incentives for receivers as well as freight operators, however, there has been only limited attention to this topic in the literature. Panero, Shin, and Lopez (2011) examined 39 existing UCCs according to multiple factors such as economic profile, the nature of goods accepted, areas served, vehicles used, type of leadership, existence of favorable regulations (or supporting policies), their compulsory or voluntary nature, and temporary or permanent scope. They pointed out that legislative measures implemented by local authorities can help the development of UCCs in two ways; either UCCs can cope better with restrictions if they use appropriate resources (e.g. low emission vehicles) or restrictions can be lifted for the UCCs' vehicles. Lebeau et al. (2017) drew on the work of Panero, Shin, and Lopez (2011), but focused purely on the role of supportive policies, and expanded the analysis to 61 UCCs. Lebeau et al. (2017) divided the potential policies into financial support (startup, structural and indirect), direct regulatory support (one compulsory UCC, license granted to transporters and favourable measures to UCC operator) and indirect regulatory support (time windows, weight restrictions, size restrictions, EURO norms, age of vehicles and urban toll). We consider the former two categories to relate more to the overall business and financial model, while the third category relates to supportive transport policies. Both will be considered in this paper.

It should also be recognised that there is a fine line between encouraging stakeholders to use UCCs and cooperate during projects and obliging them to use UCC by implementing other policies. Local authorities should implement policies that will not result in increasing the cost of transport, which later will be reflected in the costs of receivers and freight operators (Van Duin et al. 2018). Local authorities need to analyse cultural, economic and political drivers that affect their choice of policies and their public acceptability. While local authorities see restrictions (e.g. time window, size) 
as useful tools to increase the use of UCCs, freight operators may see such restrictions as an inefficient way of initiating UCCs. In addition, operators can argue that shippers should be able to choose how their products will be shipped and they can tailor their operations according to the market's demands (Van Duin et al. 2018).

A few authors have examined specific policies in case studies. Marcucci and Danielis (2008) showed that the share of traffic attracted to a UCC can be increased by implementing policies such as full public subsidy (29\% increase), increasing access fees to limited traffic zone (27\%) and a mix of these policies (as high as 78\%). Ville, Gonzalez-Feliu, and Dablanc (2013) studied a case of a UCC in Vicenza, where the local authority limited the access to limited traffic zones in order to promote the use of the UCC. These restrictions imposed by the public authority led freight operators to challenge this decision in court as they found the restrictions to be barriers to running their operations effectively under fair conditions. Allen et al. (2014) found that the local authorities in Bristol granted UCC vehicles access to bus lanes in the trial period of the scheme, with the aim of shortening delivery times to the shops. Björklund, Abrahamsson, and Johansson (2017) studied Lucca Port UCC in Italy, where the entrance to the area is restricted by fees as a part of local traffic regulations. The local authority of Lucca offers financial incentives to logistics service providers, who want to transfer their deliveries through the UCC. The authors found that the fees and the incentives were vital for the long-term commercial viability of the UCC. Marcucci and Gatta (2017) measured the willingness to accept offhour deliveries (OHD) in Rome. The authors measured retailers' responses for assisted OHD, unassisted OHD and the use of OHD in combination with the use of UCC. Their results showed that the combination of OHD and UCC was the most preferred method across the retailers.

\section{Service offerings at UCCs}

According to Björklund, Abrahamsson, and Johansson (2017), a viable business model for a UCC should be able to adapt to a dynamic environment and innovate new services in order to generate more revenue. Business models need to ensure the balanced distribution of costs and risk among the stakeholders (Johansson and Björklund 2017), often involving a public subsidy to guarantee that users will not be penalised financially, at least in the start-up phase (Allen et al. 2014). Each UCC user, whether a logistics service provider or a retailer, seeks to obtain financial and operational benefits. Benefits can vary based on the type of users; for instance, logistics service providers could send fewer vehicles to busy city centres as they subcontract a part of their last mile deliveries to UCCs. Retailers can benefit from service offerings such as storage and labelling (Johansson and Björklund 2017). These service offerings can become additional sources of revenue for UCCs as retailers usually pay for 
services offered by UCCs. In addition, the ability of developing service offerings indicates that UCCs are able to develop and adopt their business models to a dynamic environment, which is characterized by different expectations and requirements of different stakeholders (Björklund, Abrahamsson, and Johansson 2017). Existing studies mention a variety of services that can be offered by UCCs such as providing off-site storage space, pre-retailing activities, waste management and recycling, e-commerce services, information system enabling tracking and tracing, and customized delivery days and times for the users (Browne et al. 2005; Johansson and Björklund 2017).

In one of the earlier and the most comprehensive studies of UCCs, Browne et al. (2005) argued that UCCs help retailers to reduce the need for storage and logistics activities in their premises by offering storage facilities and pre-retailing services in advance. Aastrup, Gammelgaard, and Prock1 (2012) conducted a case study on retailers in Copenhagen to investigate third party logistics services in the context of city logistics and identified that a UCC can offer its receivers the flexibility of influencing delivery times. Similarly, Paddeu (2017) identified that the most popular UCC services used by retailers are storage and recycling of packaging, but other benefits of using the UCC related to being able to set delivery times and ensuring product safety. On the contrary, Johansson and Björklund (2017) did not identify a need for flexible deliveries and a demand for handling waste management. The authors also identified that reduced expenses due to using service offerings do not convince retailers to pay for using UCCs, and therefore suggested that the first step should be to understand actual logistics needs of retailers and to identify potential venues that will provide economic advantages when particular services are outsourced to UCCs. Gammelgaard, Andersen, and Figueroa (2017) also mentioned the importance of understanding the rationality of retailers' systems and improving communication of potential service offerings, thus involving retailers as stakeholders in co-creating value.

\section{METHODOLOGY}

According to Yin (2011), a case study methodology is appropriate when researchers want to define research topics broadly, cover complex multivariate conditions and rely on multiple sources of evidence. The latter two aims are clearly suited to this paper. Similarly, case studies enable researchers to make an in-depth exploration of complex phenomena (Eisenhardt 1989), and in particular qualitative case studies are one of the most suitable approaches for elaborating an existing theory or building new theory (Fawcett et al. 2014). Therefore, for this research we adopted a qualitative case study research methodology. This study adopted a multiple case study design, in which two UCC projects comprise the units of analysis. The sample selection was based on finding a more active and a less active country 
in terms of managing and regulating UFT, thus one case is from Sweden (Gothenburg) and the other is from Scotland (Perth). The City of Gothenburg in Sweden has an active UCC while the UCC project in Perth was terminated just before its trial period started. It is often difficult to identify and gather data on failed cases thus the Perth case can be equally as instructive as the successful Gothenburg case.

In order to enable data triangulation, two types of data were collected: secondary data (project reports, feasibility studies, news articles) and primary data (interviews). Interviews are an essential source of information in case studies, yet respondents' answers might be subject to bias, poor recall or poor articulation. Therefore, data obtained from interviews were corroborated with additional information from other sources (Yin 2014), which were obtained through web search and during the interviews.

The collection of primary data was achieved through semi-structured interviews.

The identification of interviewees began with the UCC project initiators and resulted in finding the operators and users directly involved in the UCC. Finding the stakeholders for Perth's UCC was particularly challenging as the UCC was never opened and some of the stakeholders were no longer accessible. Nevertheless, in both cases we interviewed the same types of respondents, from initiators, users, government and industry representatives and independent experts. This range of interviewees thus includes not just those directly involved in establishing the UCC but key representatives for providing the wider context. These actors include regional and national government representatives with responsibility for UFT, independent experts on UFT and UCCs in each country and additional industry representatives. All these respondents are knowledgeable not only regarding the general UFT context in the respective city/country but also have knowledge of the respective UCC projects. Table 1 presents the list of interviewees, their roles within the UCC projects, their organizations and their positions. A total of 23 interviews, face-to-face and by telephone, were conducted between April and June 2017. The interview guide was based on the categories identified in the literature review (and used in the analysis). The interviews lasted between 30 and 90 minutes. All interviews were recorded and transcribed.

Following the guidance of da Mota Pedrosa et al. (2012), the analysis of the data was done in multiple stages. The first step was coding both primary and secondary data based on the literature categories that formed the basis of the analysis: challenges, stakeholder collaboration, service offerings and supportive UFT policies. Coded data were then compared in order to see the similarities and differences across each case study and then integrated with the theoretical categories. Integration and iteration were executed in parallel because it was necessary to go back and forth between the data and theoretical categories in order to verify the validity of identified categories. Refutation was the last stage of the data analysis and was where the secondary data became particularly important. The 
information gathered through document review was used to confirm statements made by the interviewees. This meant that when analysing the primary data, the authors occasionally contacted the interviewees to clarify and verify some of the information. In addition, the initial results of the study were presented at a conference for further discussion with experts in the area. Data saturation was achieved when no further gaps remained, and we had obtained sufficient data for each case against each of the four conceptual categories.

Table 1. List of interviewees for the case studies

\begin{tabular}{|c|c|c|c|}
\hline $\begin{array}{l}\text { UCC } \\
\text { project }\end{array}$ & $\begin{array}{l}\text { Role within the UCC } \\
\text { project }\end{array}$ & Organization & $\begin{array}{l}\text { Position of the } \\
\text { interviewee }\end{array}$ \\
\hline \multirow{14}{*}{ 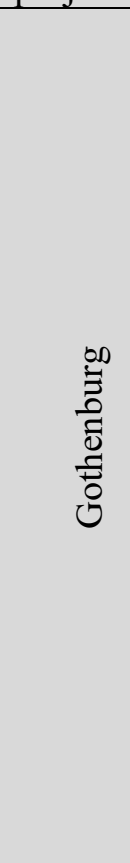 } & \multirow[t]{2}{*}{ Project Initiator } & Local Authority & Senior transport planner \\
\hline & & $\begin{array}{l}\text { Association of Real Estate and Store } \\
\text { Owners }\end{array}$ & $\begin{array}{l}\text { Finance and Marketing } \\
\text { Responsible }\end{array}$ \\
\hline & Consultant & Consultancy Company & Project Manager \\
\hline & UCC Operator & Local LSP & Owner \\
\hline & First Level Customer & International LSP & $\begin{array}{l}\text { Business Process } \\
\text { Manager }\end{array}$ \\
\hline & \multirow[t]{4}{*}{ Second Level Customer } & Local Retailer 1 & Owner \\
\hline & & Local Retailer 2 & Owner \\
\hline & & Local Retailer 3 & Owner \\
\hline & & Local Retailer 4 & Shop Manager \\
\hline & \multirow[t]{2}{*}{ Government Authorities } & National Transport Authority & Strategic Planner \\
\hline & & Regional Transport Authority & $\begin{array}{l}\text { Strategic Planning } \\
\text { Officer }\end{array}$ \\
\hline & $\begin{array}{l}\text { Project Partners with UCC } \\
\text { Initiator }\end{array}$ & Research Institute & Ex Project Manager \\
\hline & \multirow{2}{*}{$\begin{array}{l}\text { Expert on UFT and UCCs } \\
\text { in this Country }\end{array}$} & Academic Institution/University & Senior Research Fellow \\
\hline & & $\begin{array}{l}\text { Research and Technology Unit of a } \\
\text { Private Organization }\end{array}$ & Project Manager \\
\hline \multirow{9}{*}{ Е } & Project Initiator & Regional Transport Authority & Senior Transport Planner \\
\hline & $\begin{array}{l}\text { Initial Supporter and } \\
\text { Partial Funder }\end{array}$ & Local Authority & Senior Transport Planner \\
\hline & $\begin{array}{l}\text { Potential First Level } \\
\text { Customer }\end{array}$ & National LSP & $\begin{array}{l}\text { Freight Development } \\
\text { Manager }\end{array}$ \\
\hline & $\begin{array}{l}\text { Potential Second Level } \\
\text { Customer }\end{array}$ & Local Logistics Provider & Owner \\
\hline & Government Authorities & National Transport Authority & Policy Advisor \\
\hline & \multirow[t]{2}{*}{ Industry Associations } & National Industry Association 1 & Head of Policy \\
\hline & & National Industry Association 2 & Business Unit Director \\
\hline & \multirow{2}{*}{$\begin{array}{l}\text { Expert on UFT and UCCs } \\
\text { in this country }\end{array}$} & Academic Institution/University & Professor \\
\hline & & National Retailer in the UK & $\begin{array}{l}\text { National Transport } \\
\text { Strategy Manager }\end{array}$ \\
\hline
\end{tabular}




\section{CASE STUDIES}

\section{Gothenburg, Sweden}

\section{Case background}

The UCC is a subproject under the following two projects: Sendsmart funded by a national funding body between September 2012 and September 2014 and SMARTSET co-funded by the Intelligent Energy - Europe II Programme (IEE II) between May 2013 and April 2016. The aim of the Sendsmart project was to develop sustainable solutions for freight transport in Gothenburg by enabling (i) collaboration and information sharing between public and private actors, (ii) using IT and relevant technology to increase road safety and decrease environmental impact of freight operations and (iii) implementing policies and incentives for freight consolidation in order to achieve increased fill rates, reduced congestion and increased coordination (Lindholm 2014). The UCC was involved in SMARTSET in order to expand freight consolidation in the city and to develop a financially viable business model, which can be replicable in Gothenburg as well as in other European cities (Ablasser et al. 2016).

The UCC aims to reduce the amount of freight traffic during peak hours in a particular geographical area and to decrease the interference between freight vehicles and pedestrians as well as cyclists. The UCC in Gothenburg plays a crucial role as a platform that enables collaboration between the local authority, private companies, research institutes and the association of real estate owners and merchants, called Innerstaden. The UCC is owned by Innerstaden and operated by a local courier. Innerstaden is a company owned by the Buyers and Real Estate Owners Association (Köpmannaförbundet och Fastighetsägarna GFR in Swedish). Two logistics companies are the customers of the UCC, which send a part of their parcels through the UCC to the final receivers. The UCC operates for the retailers located in an area called Domkyrkoplan in the inner city of Gothenburg. The retailers located in this area specialize in clothing, footwear, food (e.g. restaurants, cafes), grocery and other consumer goods. The UCC provides the delivery service to the retailers in the area except the ones that are specialized in food and perishable goods. The UCC uses three electric cars with trailers and two electric cargo bikes to make its deliveries. They deliver and pick up 500 packages to/from approximately 200 shops on average every day. The development process of the UCC consisted of three stages: concept, development and establishment. The concept stage started in 2012 by establishing a pilot study between 2012 and 2013 with a small number of shops. At this stage, the UCC was funded by Sendsmart, the local authority and Innerstaden. The development phase took place 
between 2014 and 2016. The stakeholders focused on increasing the number of users and started to develop value-adding activities during this stage. The local authorities made an agreement with an international haulier and the national mail service to transport some parts of their deliveries through the UCC. At the end of this phase, the UCC started to fund itself by $80 \%$ and $20 \%$ was obtained from the local authority. The UCC obtains its revenue from its users and from the advertisements that are shown on the vehicles. The establishment phase started in 2017 as the final stage of the development. The UCC aims to serve all businesses in the area and they are planning to become a fully commercial business.

\section{Challenges}

The most common challenges were collaboration, finance, delivery schedules and the lack of technology. Collaboration between the stakeholders was mentioned on multiple occasions but this emerged once the project was operational. Lack of communication, engagement with the businesses, establishing a clear structure for sharing costs and operational risks, and losing the direct contact with the end customer due to using the UCC are the main points raised by the stakeholders. The stakeholders experienced financial challenges during both development and operational phases of the project. Unwillingness to pay for using the UCC, small number of logistics operators using the UCC, extra costs arising due to extra handling at the UCC and lack of demand are the main financial challenges that the stakeholders experienced. Even though the owner of the UCC and the local authority have solved the challenges concerning insufficient demand gradually, the businesses are hesitant if they would continue using the UCC when they need to pay for the last mile shipment. Regarding delivery schedules, the businesses mentioned that either they could not receive their deliveries as early as they used to, or they do not know when the vehicles will arrive during the day. Moreover, as the number of users and the volume has increased, tracking and tracing became problematic. The operator and the local authority stated that the lack of the use of information technology constrained the ability of obtaining more customers, the latter commenting that: "if we are going to work with more transport operators, we need one system which can handle different packages from different operators." Similarly, the operator discussed the challenge of scanning parcels: First, we started with a single hand scanner for both of our customers. With one computer, it is very difficult to do that. We are working on now, but we have not found a solution yet. Now we have one scanner for each customer." The lack of information system causes complaints raised by buyers of some online items, as they cannot track their items, as stated by one retailer: "If we would like to track a parcel, we put in the tracking number and it looks like it has been delivered but it has been delivered to the UCC not to us. We cannot track 
it all the way and our customers cannot either because they can see it when the parcel only arrives at the facilities of the logistics service provider."

Some other challenges were specific to some stakeholders. Some of the businesses that the UCC serve have high-value products such as high-value accessories. These businesses are concerned with damages that may occur to their products as a result of extra handling. They also mentioned that the design of the vehicles should be improved in order to ensure the protection of the goods. The operator raised the issue that it becomes problematic to find a suitable place to run their operations as their operational volume increases. One of the users of the UCC is an international freight operator. They use the UCC for a part of their deliveries, and they want to increase the volume of the goods shipped through the UCC; however, the small scale of the operator was a constraint. The scale of the operator and the profiles of the users and the customers do not lead to implementing value-adding operations in order to generate revenue. The local authority also mentioned the lack of more valueadded activities as a challenge to further growth.

\section{Stakeholder collaboration}

While some collaboration challenges emerged later, in fact collaboration played a positive role during the development of the UCC, in which the local authority provided supportive policies as well as financial subsidy. The interviewee from the local authority mentioned that they aim to become a role model to incentivize more sustainable solutions by other freight operator and businesses in the city: "We, as the local authority, want logistics service providers operating in the city to come with two principles; first, it should be clean vehicles of course preferably electric ones and we want them to provide consolidation services that it is possible for other transport companies to use." The local authority also considers building knowledge about freight and its impacts on the economy as well as the environment can be realized through collaboration with other public and private stakeholders. Therefore, the local authority prioritizes involvement in national and international projects.

The UCC started in the context of a project funded by a national authority, which initiated a platform for the stakeholders to work together. The local authority focused on some of the big logistics companies instead of individual businesses with lower volumes to establish their customer base. This large LSP provided the required amount of freight to start operations. In order to communicate with the businesses in the area, the project involved the association of real estate owners and businesses, which had a key role to include the shops located in the area in the UCC. Another strong aspect of the UCC was to involve a local transport company, which is familiar with the city, the aforementioned area and the types of businesses. Later, the local authority provided its support for the UCC by 
implementing supportive policies, in particular exempting UCC users in some cases from many of the existing transport policies in the area, such as pedestrianized areas, walking speed zones, time window restrictions and weight restrictions. The electric vehicles and the bikes used by the UCC are exempt from all the restrictions. The stakeholders continue to work together to help the UCC to become a fully commercial business.

\section{Supporting policies}

Time window restrictions (combined with weight restrictions) are in place in the area that the UCC serves and most of the area is pedestrianized. Walking speed zones (where vehicles must drive at walking speed) are in action in parts of the area that are not pedestrianized. The operator mentioned that these restrictions helped them to increase the use of the UCC as the vehicles used by the UCC are exempt from some of the restrictions in the area such as time window restrictions as well as the weight restrictions. However, one of the users of the UCC mentioned that even though they ship part of their goods through the UCC, they still need to visit certain areas in the city to deliver palletized or heavy items and the current time window and weight related restrictions constrain these operations. There are contradicting responses across the stakeholders for the policies that should be implemented in the near future. One of the interviewees mentioned that heavy goods vehicles should be allowed on the roads during off-peak hours for better capacity utilization. The same interviewee also mentioned that the local authorities should start certification programs instead of implementing restrictions for particular vehicles. On the other hand, the municipality mentioned that time windows for heavy goods vehicles and light goods vehicles should be extended in order to reduce congestion and provide more space for other road users. Some of the businesses were concerned with congestion problems in the areas where freight vehicles are allowed to enter and according to one of the businesses, there is a need for parking regulations in order to avoid congestion.

\section{Service offerings}

Businesses involved in e-commerce mentioned that flexibility in deliveries and pick-ups provided strong motivations to keep working with the UCC, although one business complained that deliveries to their store were not as well planned as before. The stakeholders also mentioned the importance of using electric vehicles as it provides environmental benefits by reducing emissions. 


\section{Perth, Scotland}

\section{Case background}

The project initially focused on implementing a consolidation centre to serve two Scottish cities in close proximity, Perth and Dundee. In both cities, improving the air quality was the primary driver for the project. Dundee opted out of the project after they revised their policy plans concerning air quality and freight. The idea of the consolidation centre in Perth was driven also by the need for reducing congestion and enhancing road safety. The project started as a result of the Air Quality Grant that Perth \& Kinross City Council obtained in 2010. The city council in Perth started to take actions to mitigate the problems concerning the air quality first by declaring Air Quality Management Areas in Perth. Later the city council developed an action plan to mitigate the air quality related problems. One of the actions was to investigate potential policies to achieve the objectives of the plan. The consultation process identified a UCC as the most favourable solution. However, the city council did not have the expertise to work on freight consolidation and brought the regional transport partnership (TACTRAN) on board to do the further investigations. At the same time, the city council hired consultants funded by the grant obtained from the Scottish government. The consultants helped TACTRAN to collect information about the retailers in the area and to complete traffic modelling in order to see the outcome of consolidation activities and low emission vehicles (TACTRAN 2010).

Based on the findings from a survey of retailers, TACTRAN and the city council decided that the UCC needed to target small and medium sized retailers, which receive a larger number of small deliveries. They wanted to consider only non-perishable goods, because they do not require specific infrastructure and systems in the UCC. Value-added services such as waste collection, off-site storage and pre-retailing services were also considered to create revenue streams for the UCC. A single retailer in Perth and Dundee was receiving 5.5 and 4.5 deliveries per week respectively. Based on the number of retailers and the average weekly deliveries, the models estimated that 24 vehicles would use the UCC against 96 vehicles delivering directly to retailers in Perth, with Dundee deliveries showing 28 UCC deliveries and 132 direct to customers. In Perth, 24 vehicles would be replaced by a single electric vehicle, which would make 3 rounds of deliveries. In Dundee, 28 vehicles would be replaced by a single electric vehicle, which would make 4 rounds of deliveries.

TACTRAN started the tendering process after traffic models showed positive effects of the UCC such as $19 \%$ overall emissions reduction through the use of electric vehicles. The city council prepared the contracts for the tendering process. Two logistics companies initially showed interest in 
operating the UCC but later withdrew because they found the project not feasible. The tendering processes was then terminated.

In the very beginning, the public stakeholders did not intend to provide public subsidies at any stage of the development. However, they changed their strategy after the failed tendering process. Shortly after, TACTRAN was involved in an EU project called LaMilo in 2014 and TACTRAN decided to fund the UCC project for 18 months during its trial period through the project and the Air Quality Grant. During the trial, retailers could have joined the scheme without paying fees. The management and the UCC was planned to be assigned to a single logistics operator and the potential operator would pay some of the costs (i.e. building, rent and workforce). Electric vehicles were also considered to operate between the UCC and the delivery points. After the UCC was included in LaMilo, TACTRAN organized events to attract the attention of the retailers and the businesses in town. However, there was no interest from the private sector. Later, a real estate company offered a social enterprise model, where the UCC would be used to consolidate and distribute the city council's stationery items in Dundee using electric vehicles. According to the principles of the social enterprise model, the revenue should be paid back to the community. Eventually this project was also terminated due to problems with the stationery suppliers, their existing contracts and the lack of support from the local authority in Dundee.

\section{Challenges}

The biggest challenge was the lack of interest from a suitable logistics operator to run the UCC caused by financial constraints and the lack of collaboration among stakeholders. The financial constraints were the lack of customer base, the cost of adding one more segment to supply chains, and the cost of extra handling for goods that are already consolidated. Thus, without subsidy, the project could not provide an advantageous pricing scheme to establish a sufficient customer base. As a part of the project, the stakeholders tried to establish a business model and then identify a private freight operator, which would undertake the required investments and receive the revenue. However, the planned business model was not able to clarify key elements such as the particular property for locating the UCC, the ownership and the use of low emission vehicles.

Political barriers were another significant challenge. The project could not obtain financial support from public authorities such as the local authority and the national government because freight transport and related air quality concerns were not high on national and local agendas at the time when the project was on the table. The local authority mentioned that "I think things are changing with regards to the air quality side of things. People are starting to take on board that air quality has health 
hazards; it is a major problem within our cities. I think this is one of the main points that air quality was not in the political agenda as it is now in the last couple of years."

In terms of collaboration, the regional transport partnership TACTRAN was the main driving force behind the project with some help from the local authority during earlier stages of the development. Despite the initiatives to bring potential users to the table at earlier stages, the lack of contact with local businesses was an ongoing challenge that ultimately could not produce a customer base.

\section{Stakeholder collaboration}

Collaboration was one of the missing links in this UCC project. TACTRAN attempted at various times to trigger collaboration in the project through different channels, such as including it in an EU project. However, the potential freight operator ended their agreement before the trial started. Some of the stakeholders stressed the importance of collaborating with local businesses, which were mostly small and medium enterprises: "retailers that are receiving limited number of deliveries per day through the parcels delivery system were what we were aiming at." Some potential users were actually concerned about the development, one logistics provider commenting: "I do not know if I would like to be involved actually. I would say if there was a consolidation centre it's probably more likely take business away from my business here unless actually, I was physically involved with it in terms of investment or moved my business to the consolidation centre."

After the unsuccessful tendering process, TACTRAN had various attempts in order to continue with the implementation of the project. The UCC project has become the part of the EU projects and TACTRAN wanted to initiate the involvement of various stakeholders through this project but there was no interest from the private actors including the retailers and the businesses. The social enterprise project had to end due to the lack of support and the collaboration from the local authorities in Dundee.

\section{Supporting policies}

Transport policies at the local, regional and national levels have a limited scope concerning UFT in Scotland. National level documents have provided the information concerning general freight issues. The local authorities in Perth and Dundee have objectives to improve the efficiency of freight transport systems in their cities. However, there is a lack of understanding of UFT issues among local planners (TACTRAN, 2010). In addition, the Regional Transport Strategy included some recommendations concerning how to develop UFT in the cities such as establishing a freight quality partnership and identifying cost effective freight policies. Moreover, when TACTRAN changed the scope of the project from being a commercial UCC to being a social enterprise, which was supposed to work for 
the public goods deliveries for Dundee's city council, the role of public authorities had the opposite effect during the development stage. The city council in Dundee did not support the project due to financial constraints.

The interviewees representing freight operators and retailers mentioned that the local authority should remove the ban on night time deliveries and enable freight operators to retime their deliveries during off-peak hours or during the night. They also complained that existing parking enforcements compromise loading and unloading bays when non-freight vehicles park on them illegally, and that additionally they would like more designated bays. The majority of private actors do not favour policies that implement restrictions and pricing schemes (e.g. congestion charge). TACTRAN and the local authority recommended some policies which they hoped might incentivize users and freight operators to utilize the UCC, such as the development of delivery and service plans, parking privileges for electric vehicles and enabling off-peak deliveries. The feasibility report also explicitly raised the possibility of considering options such as tighter restrictions with respect to time, size and route, exemptions from restrictions for certain delivery vehicles, promoting fleer recognition schemes and reduced business rates (local tax for businesses) for potential users of the UCC (TACTRAN 2010).

\section{Service offerings}

TACTRAN focused on a UCC concept that would cover the deliveries for local retailers, mainly the ones which sell non-perishable goods. During feasibility studies (TACTRAN, 2010), TACTRAN drew attention to the importance of offering additional services in order to provide additional revenues, which could help the UCC to become financially viable as quick as possible. The feasibility report proposed service offerings that would be particularly useful for retailers such as collection of waste and recyclable materials, pre-retailing services (e.g. tagging, barcoding, preparing items for display) and providing storage space. The discussions about the service offerings were not taken further as the project terminated at an early stage. If the project had gone ahead, it was planned to use electric vehicles for deliveries, which would have been another potentially attractive service.

\section{CROSS-CASE ANALYSIS}

Table 2 summarizes the main findings of the study. The following sub-sections will briefly highlight the key findings in the cross-case analysis and the discussion section will discuss them in the context of previous research. 
Table 2. Summary of the main findings from each case study Influences $\quad$ Gothenburg

\begin{tabular}{|c|c|c|c|c|}
\hline \multicolumn{3}{|c|}{ Influences } & Gothenburg & Perth \\
\hline \multirow{2}{*}{\multicolumn{2}{|c|}{$\begin{array}{c}\text { Challenges identified in the } \\
\text { cases }\end{array}$}} & Financial viability & $\begin{array}{l}\text { Yes (only during operational } \\
\text { rather than development phase) }\end{array}$ & Yes \\
\hline & & Operations & Yes & No \\
\hline \multirow{3}{*}{\multicolumn{2}{|c|}{$\begin{array}{l}\text { (Browne et al. } 2005 \text {; Allen et al. } \\
2014 \text {; Kin et al. 2016; } \\
\text { Johansson and Björklund 2017; } \\
\text { Lagorio, Pinto, and Golini 2016) }\end{array}$}} & Lack of collaboration & $\begin{array}{l}\text { Yes (only during operational } \\
\text { rather than development phase) }\end{array}$ & Yes \\
\hline & & Lack of political support & No & Yes \\
\hline & & Location and infrastructure & $\begin{array}{l}\text { Yes (only during operational } \\
\text { rather than development phase) }\end{array}$ & Yes \\
\hline \multirow{4}{*}{\multicolumn{2}{|c|}{$\begin{array}{l}\text { Stakeholder collaboration factors } \\
\text { identified in the cases }\end{array}$}} & Need for public action & Yes & Yes \\
\hline & & Awareness of barriers & Yes & Yes \\
\hline & & Build on large players & Yes & $\begin{array}{l}\text { No (attempted but } \\
\text { not achieved) }\end{array}$ \\
\hline & & Empower small players & Yes & No \\
\hline \multirow{3}{*}{\multicolumn{2}{|c|}{$\begin{array}{c}\text { Service offerings from each } \\
\text { UCC }\end{array}$}} & Electric vehicles & Yes & Yes (intended) \\
\hline & & Additional stockholding & No & Yes (intended) \\
\hline & & Pre-retailing services & No & Yes (intended) \\
\hline \multirow{5}{*}{\multicolumn{2}{|c|}{$\begin{array}{l}\text { (Browne, Allen and Leonardi } \\
\text { 2011; Paddeu 2017; Johansson } \\
\text { and Björklund 2017; Björklund, } \\
\text { Abrahamsson, and Johansson } \\
\text { 2017; Gammelgaard, Andersen, } \\
\text { and Figueroa 2017) }\end{array}$}} & Waste management \& recycling & No & Yes (intended) \\
\hline & & E-commerce services & Yes & No \\
\hline & & $\begin{array}{c}\text { Using vehicles as the venue for } \\
\text { advertisement }\end{array}$ & Yes & No \\
\hline & & $\begin{array}{l}\text { Information system enabling } \\
\text { tracking and tracing }\end{array}$ & Yes (not currently but in progress) & No \\
\hline & & $\begin{array}{c}\text { Customized delivery times and } \\
\text { dates }\end{array}$ & $\begin{array}{l}\text { Yes (but only for some deliveries, } \\
\text { not all) }\end{array}$ & No \\
\hline \multirow{12}{*}{$\begin{array}{l}\text { Supportive } \\
\text { policies applied } \\
\text { in each case } \\
\text { (Panero, Shin, } \\
\text { and Lopez 2011; } \\
\text { Lebeau et al. } \\
\text { 2017) }\end{array}$} & \multirow{3}{*}{$\begin{array}{l}\text { Financial } \\
\text { support }\end{array}$} & Start-up & Yes & No \\
\hline & & Structural & Yes & $\begin{array}{l}\text { No (attempted but } \\
\text { not achieved) }\end{array}$ \\
\hline & & Indirect & No & Yes \\
\hline & \multirow{3}{*}{$\begin{array}{l}\text { Direct } \\
\text { regulatory } \\
\text { support }\end{array}$} & One compulsory UCC & No & No \\
\hline & & License granted to transporters & No & No \\
\hline & & $\begin{array}{l}\text { Favourable measures to UCC } \\
\text { operator (including off-peak } \\
\text { deliveries) }\end{array}$ & Yes & Yes (intended) \\
\hline & \multirow{6}{*}{$\begin{array}{l}\text { Indirect } \\
\text { regulatory } \\
\text { support }\end{array}$} & Time windows & Yes & Yes \\
\hline & & Weight restrictions & Yes & No \\
\hline & & Size restrictions & No & No \\
\hline & & EURO vehicle norms & Yes & No \\
\hline & & Age of the vehicles & Yes & No \\
\hline & & Urban toll & Yes & No \\
\hline
\end{tabular}

Notes: The Perth case was never operational, so the service offerings and supportive policies listed are those that were intended. 


\section{Challenges}

The Perth case experienced the major challenges of finance, collaboration and location early, which is why it was unsuccessful, whereas these were raised only later during the operational phase of the Gothenburg case. It overcame these challenges in the development phase through start-up funding and an ongoing collaboration, but once the UCC was operational, maintaining funding became harder. In addition, the location became less attractive due to changing demand and operational challenges. A more complex supply chain weakened the collaboration in which the retailer, the operator and the local authority occasionally experienced problems in communication.

The operational challenges are important to highlight as they are the cause of the reluctance of LSPs to use UCCs and lead to the need for collaboration, service offerings and supportive policies discussed in the next sections. Extra handling at the UCC was considered a challenge by the LSPs outsourcing their last mile deliveries to the UCC, firstly because of the obvious fact of needing to pay to the UCC for each package that the UCC delivers: "We know that if you handle goods or parcels one more time, it will cost some money . . but sometimes if you want to develop things you need to invest." Another important issue was losing direct contact with customers, which can affect the service levels of LSPs, as they will lose control over the quality and timeliness of deliveries. The operator commented: "We have some service problems with some of the receivers. . . Earlier you were A and received your product at 10 am but now you are $B$ receiving products at 2 pm and that is not positive for the company."

The Gothenburg UCC was able to provide some operational benefits by decreasing the number of vehicles that providers were sending to the area as they make their deliveries to the UCC using bigger trucks instead of sending multiple smaller trucks to the area, where time window and weight restrictions are in place.

\section{Stakeholder collaboration}

In both cases, the projects were initiated by local authorities, which obtained some funding from national and international sources, and then identified the potential stakeholders for the UCC. Yet the role of collaboration was quite different between the case studies. The lack of collaboration is one of the primary reasons why the UCC in Perth was terminated. The project went through stages where different business models were discussed but they did not develop further as each model lacked support from each of the three stakeholder groups, but particularly from LSPs. In contrast, the Gothenburg case showed evidence of all of the four collaboration factors. The local authority initiated the proposal and then approached local businesses in order to discuss the potential barriers that the project may 
encounter and the particular requirements of these businesses. The project developers negotiated with large logistics service providers to become users of the UCC. Finally, the local authority approached a small sized local courier to hire them as the operator of the UCC. In this way, the local authority has created a job opportunity for a small-scale business, which does have experience in working with the local businesses and is familiar with the area. The UCC in Perth began with public action but did not display sufficient awareness of the barriers to using a UCC and thus was not able to attract either users or an operator. After the project was terminated, the public authorities in Perth highlighted the importance of establishing collaboration with local logistics service providers instead of large national and international companies while searching for an operator for the UCC.

Nevertheless, it is important to note that, even in the successful case, in fact the private operators (the users) were not initially eager to join the project. The involvement of the public sector was particularly influential by providing financial support and enforcing particular restrictions in the areas, and also the evolution of the local transport policies after the implementation of the UCC. Thus, the evolution of UFT policy worked in conjunction with the stakeholder collaboration. On the other hand, in the Perth case the public stakeholder was unable to attract interest on behalf of the private sector, which could be partly because of their lack of introducing supportive policies but also due to limited collaboration between the public and private stakeholders when it comes to dealing with UFT related issues in Scotland. The comment quoted earlier from a Scottish LSP which viewed the UCC as a potential threat gives on indication of this challenge.

\section{Supporting policies}

The table shows some clear differences between the successful and unsuccessful case. Clearly the start-up finance was absolutely essential, reflecting the challenges of attracting paying users. To avoid increasing costs for users and to attract an operator, the Swedish project was subsidized by public money beginning from the early stages of the project and the support was decreased gradually as the UCC started to generate revenues. However, the UCC will continue to receive structural subsidy until it becomes a fully commercial business. Indirect financial support was available in Perth via an EUfunded research project that paid for the feasibility studies. Direct regulatory support was provided (or planned) in both cases via favourable measures to the UCC operator. Another key difference was in the indirect regulatory support, which is where the list of supportive or other UFT policies can be used in conjunction with the UFT. The UCC in Perth focused on the "carrot" of attracting paying customers but without the "stick" of restrictive UFT policies that would effectively force them to use the UCC to avoid them. This was partly due to political challenges: "it is just very difficult to get the politicians to 
support it and local newspapers will latch on something like that and make a big story out of that which says council is trying to impose restrictions."

It must be remembered that such restrictions are not necessarily directly for the UCC but are sometimes put in place regardless. In the Gothenburg case, the local authority implemented time window restrictions around Domkyrkoplan before the UCC has been established. The purpose of the restrictions was not to support the UCC directly but to create a pedestrianized area to increase the road safety mainly for pedestrians. After the UCC started to operate, the local authority granted access permissions for electric vehicles and bikes at any time of the day (i.e. favourable measures to the operators). Later, the local authority continued to implement other policies in combination with time restrictions. Since February 2017, weight restrictions are in place, where vehicles above 3.5 tonnes are only allowed to enter the area until $10 \mathrm{am}$. The municipality aims to increase the number of policies gradually until they minimize the number of personal and commercial vehicles in the area. The local authority in Gothenburg also implemented environmental zones (i.e. controlling age of the vehicles) and congestion charge (i.e. urban toll) to regulate the flow of general traffic, which may indirectly encourage freight companies and receivers to use the UCC. So, in this case it is the fact that the local authority in Gothenburg is proactive about reducing traffic in the city centre that created an environment where the UCC could be attractive, whereas UFT has a lower priority in public policy in Scotland generally and so in Perth such policies would have had to be newly implemented. This supports the importance of understand the public authority role and linking the wider UFT policy setting with the individual UCC development.

\section{Service offerings}

Both UCCs offered (or planned) the use of electric vehicles and cargo bikes, but, while the unsuccessful Perth case planned traditional stockholding and pre-retailing services, the Gothenburg case did not find interest from users in these services. This is because their customers are the logistics service providers rather than the receiving retailers. Instead they looked towards the use of IT, offering e-commerce now and developing tracking and tracing. The latter is particularly important because otherwise the retailers cannot track their goods after they are delivered at the UCC because they are no longer in the system of the logistics provider. Here the different information systems used by operators was a challenge, as noted by the UCC operator in the case study description above. They were able to raise revenue from using vehicles as the venue for advertisement. 


\section{DISCUSSION OF FINDINGS IN RELATION TO PREVIOUS STUDIES}

While the challenges of UCCs were not the main focus of this study but rather a contextual factor in our overall analysis of the policy issues, we can identify the main challenges in our two cases. These were financial viability, need for political support and operational obstacles (e.g. lack of delivery schedules, lack of information system infrastructure, losing first contact with the customers), the latter clearly affecting primarily the logistics service providers rather than the other two stakeholder groups. Financial viability is the obvious challenge, due to a lack of customer base and usually requires political support via public subsidy to overcome, as also found by several previous authors (e.g. Browne et al. 2005; Quak, Balm, and Posthumus 2014; Björklund, Abrahamsson, and Johansson 2017; Johansson and Björklund 2017; Kin et al. 2016). But this challenge arises in effect from the operational challenges that deter users. One of the key themes in the interviews was that logistics service providers currently serving their customers directly are reluctant to pay for the additional cost caused by adding another link to their supply chains (as also found by Allen et al. 2014; Quak, Balm, and Posthumus 2014). In addition to the pure cost issue, the logistics service providers do not want to lose the direct contact with their customers (as also found by Allen et al. 2014).

It is crucial for public-led projects to identify a potential operator and potential users for the UCC and ensure that they will not be financially penalised for using it, usually requiring public subsidy, which confirms the findings of Lagorio, Pinto, and Golini (2016). The public stakeholders should be able to show logistics service providers that they can obtain operational benefits by outsourcing their last mile deliveries, if they want to attract more users (Quak, Balm, and Posthumus 2014). In fact, the saving of transport costs by the logistics service provider in the Gothenburg case through using larger vehicles to deliver to the UCC confirms the argument of Janjevic and Ndiaye (2017) that a UCC should be able to decrease delivery costs through providing gains in terms of distance and time.

The second category of findings relates to stakeholder collaboration. According to Björklund and Johansson (2018), even though stakeholder collaboration is often mentioned in the literature, none of the studied articles went into detail describing this collaboration. Managing a large number of stakeholders with different goals, costs, and benefits of using a UCC is a challenging task. To what extent poor collaboration between stakeholders is a reason behind frequent failures of UCCs is an important question yet to be addressed. In order to fully analyse the position of each stakeholder group, a larger quantity of data would be needed through a large-scale survey of each group (e.g. Marcucci and Gatta, 2017, on retailers). Nevertheless, some conclusions can be drawn from this study regarding the perspectives of each group and their collaboration. 
According to Harrington et al. (2016), the three main stakeholder groups are local authorities, logistics service providers, and retailers, all three of which were interviewed for this study. The different perspective of each group was clear and aligned between both cases. The local authorities want to support business but equally recognise the growing need to be more proactive in achieving lower emissions in the city centre. Retailers do not have a strong opinion and simply want to continue receiving the same service they currently enjoy. LSPs would ideally prefer to be left alone by public actors, but the Swedish case showed that over time, through ongoing collaboration and to some extent the co-creation of UFT policies, they can accept the need to be involved.

While the final customer of the delivery services is the local retailers, in fact they appear to have little concern about using UCCs as there is little discernible impact from their perspective. It is in fact the logistics service providers who are the real users of the UCC. It is their business model being changed, their deliveries complicated, and they have to pay the UCC fees. This is an important finding that tends to be overlooked. The successful case showed that service offerings can be attractive but only once they are already using the UCC - the offerings themselves do not incentivize the use. This is where the public authority perspective as discussed in this paper is crucial, which has been under-researched in relation to UCCs, and only little addressed in terms of UFT in general (Akgün et al., 2019).

Van Duin et al. (2010) identified two major difficulties with the implementation of UCCs: the allocation of the costs and benefits and the willingness to cooperate of the transportation companies. They argue that, while retailers and transport companies obtain certain benefits from using services provided by a UCC, operators of UCCs incur costs of operating UCCs, thus local authorities should play a role in bringing the costs and benefits together. The conclusion from our cases is that the local authority must provide strong support, by subsidizing the start-up phase so there are no additional costs to the transport providers, and also to some degree forcing them to use it by applying traffic restrictions that are then lifted for UCC users. This lead by the public actors confirms previous studies that continue to show a reluctance from the private sector to develop UCCs (Browne et al. 2005; Van Duin, Quak, and Muñuzuri 2010; Van Duin et al. 2018). This could also indicate a need for better guidelines on the national and the local levels in order to increase the understanding of urban freight, as argued by Gammelgaard, Andersen, and Figueroa (2017). Applying the framework of four elements of good UCC collaboration identified by Van Duin et al. (2018) clearly showed that the successful UCC applied all four elements whereas the unsuccessful case failed to build on large players or empower small players. These factors relate to the UCC development process, but the findings emerging in this research underline the need for this process to build on a previous foundation of public-private collaboration and a supportive UFT policy setting, as discussed later in this section. 
The third category as well as the main focus of this study is the role of supportive policies that affect the viability of UCC projects. The start-up and structural finance were absolutely essential to the successful case, supported by favourable measures to the UCC operator. In terms of the more recognisable UFT policies that supported the UCC (termed "indirect regulatory support" by Lebeau et al. 2017), the findings confirm the previous research, showing that all but one was applied. According to interviewees, the most effective policy was to lift the existing time window restrictions for the users of the UCC.

According to Björklund, Abrahamsson, and Johansson (2017), ongoing collaboration between the local authority and industry can establish a growing evidence base which helps local authorities identify how existing policies can support the use of a new UCC and how these policies should be altered or improved over time based on the demand for transport and related value-added activities in areas served by UCCs. Compared to previous studies, the successful Gothenburg case in this paper showed the importance of having policies in place for some time before implementing the UCC. The Vicenza case studied by Ville, Gonzalez-Feliu, and Dablanc (2013) revealed a legal battle between the local authority and the association of freight transport carriers, whereas in Gothenburg the local businesses and logistics services providers were already familiar with operating under restrictive measures, as time window restrictions, weight restrictions, urban tolls, and age restrictions for vehicles had been in place before implementing the UCC scheme. While on one hand, these "supportive" policies could perhaps more realistically be considered as ways to force operators to use the UCC, in fact in the case of Gothenburg they were already in place to reduce traffic in the centre rather than being implemented specifically to support the UCC. This finding supports the importance of understanding the public authority role and linking the wider UFT policy setting with the individual UCC development which has been under researched thus far.

The final category of findings consists of service offerings that UCCs can provide to be more attractive or raise additional revenue. Value-added services and the use of electric vehicles are widely discussed in the existing literature such as pre-retailing services, waste management, e-commerce services and stockholding (Browne, Allen, and Leonardi 2011; Johansson and Björklund 2017; Paddeu 2017). The UCC in Gothenburg offered electric vehicles and e-commerce services and later developed another revenue stream via using their electric vehicles for advertising. The Perth UCC was also planning electric vehicles as well as the more traditional stockholding and pre-retailing services. One important finding was that different IT systems used by different logistics providers makes it difficult for the UCC to develop a single system for handling all of them and providing visibility to the end customer waiting for deliveries, which illustrates the contention of Björklund, Abrahamsson, and 
Johansson (2017) that utilizing the advantage of IT systems in designing and developing city logistics initiatives is one of the critical factors for building viable business models.

\section{CONCLUSION}

The key finding from this study is that supporting policies for UCCs cannot be considered in isolation from the UFT policy setting established by the local authority. While local transport policies such as time window restrictions in the city centre can support successful UCCs, they work best not as new policy measures but when put in place already by a proactive local authority. Stakeholder collaboration is the other key aspect that supports the implementation of UFT policies for UCCs. While public authorities and private companies often have different perspectives, it is possible to develop successful projects together when they are aware of the potential consequences as well as benefits of UFT policies. Crucially, stakeholder collaboration should evolve over time for successful implementation of UCCs. Thus, improving the general UFT policy setting by the local authority and particularly the collaboration between the public and private sectors are essential steps that should be taken before attempting such an undertaking. Once this improved environment and more active management of UFT is in place, a UCC development may be contemplated.

While our study showed that policies did make the UCC more attractive, even the best policies would not have been sufficient to establish the UCC without the start-up subsidy and the understanding of UFT developed by the public authorities over some years. Björklund, Abrahamsson, and Johansson (2017) state that a UCC business model should include the ability to scale up and continuously develop the system, the ability to identify key roles and supporting organisational forms and the ability to innovate new services, all of which were identified in the successful Gothenburg case. So, it is not just individual services, but the business model considered as a whole that is key.

While case study research always faces some limitations in terms of generalisability, previous case studies discussed in the literature review demonstrate their importance in understanding the challenges in UCC development, especially from a qualitative perspective, such as reluctance from users and interaction between public bodies and industry. While different types of UCCs exist (e.g. market size, distance, customer type, public or private), the two cases selected for this research were purposely selected as similar, both led by public authorities, aimed at serving retailers in pedestrianised zones where time windows restrictions are implemented. Confidence in generalisability depends on the rigour of the methodology, including the traceability of the research process, which, from the formulation of problems to the dissemination of results should as far as possible be accountable and traceable by readers (da Mota Pedrosa et al., 2012). As described in the methodology section, this 
traceability was ensured by documenting the research process and the data sources, the selection of cases, informants and data collection techniques, which can enable the reproducibility of the research process by other researchers. In terms of findings, the main factors impacting the different results for each case were not to do with the practical aspects of market or distance but were related to policy and stakeholder collaboration, and it is these findings as regards the policy environment that can be generalizable from city to city. However, this study comes with certain limitations such as number and characteristics of the cases. First, this study focuses on two cases. If the number of the cases were increased, this would improve the generalisability of the results. Second, this study only focuses on public-led UCCs. However, the dynamics of stakeholder collaboration and the type of policies that appropriately support the development of UCC projects may be different for private-led UCCs.

This study contributes to existing knowledge by demonstrating the importance of understanding the divergent perspective of all stakeholders, notably the concerns of logistics providers losing direct control of their last mile solutions, and the importance of the public authority building a collaborative UFT policy environment before attempting a UCC development. Crucially, this involves designing supportive policies for the city in general and not just for the UCC, but also committing to financially support the UCC over at least the medium term, allowing time for the system to mature and collaborative service offerings to be developed.

\section{REFERENCES}

Aastrup, Jesper, Britta Gammelgaard, and Günter Prockl. 2012. "3PL Services in City Logistics: A User's Perspective." Presented at the 24th NOFOMA Conference, Turku, June 7-8.

Ablasser, Gerhard, Simona Berlini, Michelle Coldrey, Fred Dotter, Hans Dunder, Federica Frigato, Pernilla Hyllenius Mattisson, Peter König, Malcolm Lundgren, Julius Menge, Philip Michalk, Fabio Nussio, Francesca Ravaioli, Giuseppe Siciliano, Olga Slobodova, Marco Surace, Christoffer Widegren, Tomas Widenfalk, Floor Wolfswinkel, Ann Zunder. 2016. "SMARTSET Final Report: Experiences of A European Project For Cleaner, Safer and More Efficient Freight Transport”. Available at: http://smartset-project.eu/downloads (Accessed 20 February 2018).

Akgün, Emine Zehra, Jason Monios, Tom Rye, and Achille Fonzone. 2019. "Influences on Urban

Freight Transport Policy Choice by Local Authorities." Transport Policy 75: 88-98. doi.org/10.1016/j.tranpol.2019.01.009

Allen, Julian, Michael Browne, Allan Woodburn, and Jacques Leonardi. 2012."The Role of Urban

Consolidation Centres in Sustainable Freight Transport." Transport Reviews 32 (4): 473-90. doi.org/10.1080/01441647.2012.688074 
Allen, Julian, Michael Browne, Allan Woodburn, and Jacques Leonardi. 2014. "A Review of Urban Consolidation Centres in The Supply Chain Based on A Case Study Approach." Supply Chain Forum: An International Journal 15(4): 100-12. doi.org/10.1080/16258312.2014.11517361

Ballantyne, Erica EF, Maria Lindholm, and Anthony Whiteing. 2013. "A Comparative Study of Urban Freight Transport Planning: Addressing Stakeholder Needs." Journal of Transport Geography 32: 93-101. doi.org/10.1016/j.jtrangeo.2013.08.013

Björklund, Maria, Mats Abrahamsson, and Henrik Johansson. 2017. "Critical Factors for Viable Business Models for Urban Consolidation Centres." Research in Transportation Economics 64: 3647. doi.org/10.1016/j.retrec.2017.09.009

Björklund, Maria, and Henrik Johansson. 2018. "Urban Consolidation Centre-A Literature Review, Categorisation, and A Future Research Agenda." International Journal of Physical Distribution \& Logistics Management 48(8): 745-64. doi.org/10.1108/IJPDLM-01-2017-

Browne, Michael, Michael Sweet, Allan Woodburn, and Julian Allen. 2005. "Urban Freight Consolidation Centres Final Report." Transport Studies Group, University of Westminster 10.

Browne, Michael, Julian Allen, and Jacques Leonardi. 2011. "Evaluating the Use of An Urban Consolidation Centre and Electric Vehicles in Central London." IATSS Research 35(1): 1-6. doi.org/10.1016/j.iatssr.2011.06.002

Dablanc, Laetitia. 2007. "Goods Transport in Large European Cities: Difficult to Organize, Difficult to Modernize." Transportation Research Part A: Policy and Practice 41(3): 280-85. doi.org/10.1016/j.tra.2006.05.005

da Mota Pedrosa, A., Näslund, D. and Jasmand, C., 2012. Logistics Case Study Based Research: Towards Higher Quality. International Journal of Physical Distribution \& Logistics Management, 42(3), pp.275-295.

De Marco, Alberto, Giulio Mangano, and Giovanni Zenezini. 2018. "Classification and Benchmark of City Logistics Measures: An Empirical Analysis." International Journal of Logistics Research and Applications 21(1): 1-19. doi.org/10.1080/13675567.2017.1353068

Ducret, R., 2014. "Parcel Deliveries and Urban Logistics: Changes and Challenges in the Courier Express and Parcel Sector in Europe-The French Case. Research in Transportation Business \& Management 11:15-22. doi.org/10.1016/j.rtbm.2014.06.009

Eisenhardt, Kathleen M. 1989. "Building Theories from Case Study Research." Academy of Management Review 14(4): 532-50. doi.org/10.5465/amr.1989.4308385

Fawcett, Stanley E., Matthew A. Waller, Jason W. Miller, Matthew A. Schwieterman, Benjamin T. Hazen, and Robert E. Overstreet. 2014. "A Trail Guide to Publishing Success: Tips on Writing 
Influential Conceptual, Qualitative, and Survey Research." Journal of Business Logistics 35(1): 116. doi.org/10.1111/jbl.12039

Gammelgaard, Britta, Christina BG Andersen, and Maria Figueroa. 2017. "Improving Urban Freight Governance and Stakeholder Management: A Social Systems Approach Combined with Relationship Platforms and Value Co-creation." Research in Transportation Business \& Management 24: 17-25. doi.org/10.1016/j.rtbm.2017.07.005

Harrington, Tomás Seosamh, Jagjit Singh Srai, Mukesh Kumar, and Josef Wohlrab. 2016. "Identifying Design Criteria for Urban System 'Last-Mile'solutions-A Multi-Stakeholder Perspective." Production $\quad$ Planning $\quad \& \quad$ Control 27(6): 456-76. doi.org/10.1080/09537287.2016.1147099

Janjevic, Milena, and Alassane Ndiaye. 2017. "Investigating the Theoretical Cost-Relationships of Urban Consolidation Centres for Their Users." Transportation Research Part A: Policy and Practice 102: 98-118. doi.org/10.1016/j.tra.2016.10.027

Johansson, Henrik, and Maria Björklund. 2017. "Urban Consolidation Centres: Retail Stores' Demands for UCC Services." International Journal of Physical Distribution \& Logistics Management 47(7): 646-62. doi.org/10.1108/IJPDLM-02-2017-0114

Holguín-Veras, José, Sánchez-Díaz, Iván and Browne, Michael, 2016. "Sustainable Urban Freight Systems and Freight Demand Management." Transportation Research Procedia 12: 40-52.

Kiba-Janiak, Maja. 2017. "Urban Freight Transport in City Strategic Planning." Research in Transportation Business \& Management 24: 4-16. doi.org/10.1016/j.rtbm.2017.05.003

Kin, Bram, Sara Verlinde, Tom van Lier, and Cathy Macharis. 2016. "Is There Life After Subsidy for An Urban Consolidation Centre? An Investigation of the Total Costs and Benefits of a PrivatelyInitiated Concept." Transportation Research Procedia 12: 357-69. doi.org/10.1016/j.trpro.2016.02.072

Lagorio, Alexandra, Roberto Pinto, and Ruggero Golini. 2016. "Research in Urban Logistics: A Systematic Literature Review." International Journal of Physical Distribution \& Logistics Management 46(10): 908-31. doi.org/10.1108/IJPDLM-01-2016-0008

Lebeau, Philippe, Sara Verlinde, Cathy Macharis, and Joeri Van Mierlo. 2017. "How Can Authorities Support Urban Consolidation Centres? A Review of the Accompanying Measures." Journal of Urbanism: International Research on Placemaking and Urban Sustainability 10(4): 468-86. doi.org/10.1080/17549175.2017.1310747

Lindholm, Maria. (2013). "Urban Freight Transport from A Local Authority Perspective - A Literature Review." European Transport | Trasporti Europei, 54: 1-37 
Lindholm, $\quad$ Maria. $2014 . \quad$ "Slutrapport-Sendsmart", available at: https://closer.lindholmen.se/sites/default/files/content/resource/files/slutrapport_sendsmart_slutlig .pdf (Accessed 20 February 2018).

Lindholm, Maria Eleonor, and Magnus Blinge. 2014. "Assessing Knowledge and Awareness of the Sustainable Urban Freight Transport Among Swedish Local Authority Policy Planners." Transport Policy 32: 124-31. doi.org/10.1016/j.tranpol.2014.01.004

Macharis, Cathy, and Sara Verlinde. 2012. "Sharing Urban Space: A Story of Stakeholder Support." Urban Freight for Livable Cities, The Volvo Research and Educational Foundations, VREF.

Marcucci, Edoardo, and Romeo Danielis. 2008. "The Potential Demand for A Urban Freight Consolidation Centre." Transportation 35 (2): 269-284. https://doi.org/10.1007/s11116-007-9147$\underline{3}$

Marcucci, Edoardo, and Valerio Gatta. 2017. "Investigating the Potential for Off-Hour Deliveries in The City of Rome: Retailers' Perceptions and Stated Reactions." Transportation Research Part A: Policy and Practice 102: 142-56. doi.org/10.1016/j.tra.2017.02.001

Muñuzuri, Jesús, Juan Larrañeta, Luis Onieva, and Pablo Cortés. 2005. "Solutions Applicable by Local Administrations for Urban Logistics Improvement." Cities 22(1): 15-28. doi.org/10.1016/j.cities.2004.10.003

Nordtømme, Marianne Elvsaas, Kristin Ystmark Bjerkan, and Astrid Bjørgen Sund. 2015."Barriers to Urban Freight Policy Implementation: The Case of Urban Consolidation Center in Oslo." Transport Policy 44: 179-86. doi.org/10.1016/j.tranpol.2015.08.005

Olsson, Jerry, and Johan Woxenius. 2014. "Localisation of Freight Consolidation Centres Serving Small Road Hauliers in a Wider Urban Area: Barriers for More Efficient Freight Deliveries in Gothenburg." Journal of Transport Geography 34: 25-33. doi.org/10.1016/j.jtrangeo.2013.10.016 Paddeu, Daniela. 2017. "The Bristol-Bath Urban Freight Consolidation Centre from the Perspective of Its Users." Case Studies on Transport Policy 5(3): 483-91. doi.org/10.1016/j.cstp.2017.06.001

Panero, Marta A., Hyeon-Shic SHin, and Daniel Polo Lopez. 2011. "Urban Distribution Centers: A Means to Reducing Freight Vehicle Miles Travelled." The NYU Rudin Center For Transportation Policy and Management: New York, NY. Available at: https://www.dot.ny.gov/divisions/engineering/technical-services/trans-r-and-d-repository/C-0823 0.pdf. Accessed $3^{\text {rd }}$ November 2018.

Quak, Hans, and Lori Tavasszy. 2011. "Customized Solutions for Sustainable City Logistics: The Viability of Urban Freight Consolidation Centres." In Transitions Towards Sustainable Mobility: 213-33. Berlin, Heidelberg: Springer. 
Quak, H. 2011. "Urban Freight Transport: The Challenge of Sustainability." City Distribution and Urban Freight Transport: Multiple Perspectives: 37-55, Cheltenham, UK: Edward Elgar Publishing.

Quak, Hans, Susanne Balm, and Bineke Posthumus. 2014 "Evaluation of City Logistics Solutions with Business Model Analysis." Procedia-Social and Behavioral Sciences 125: 111-24. doi.org/10.1016/j.sbspro.2014.01.1460

Stathopoulos, Amanda, Eva Valeri, and Edoardo Marcucci. 2012. "Stakeholder Reactions to Urban Freight Policy Innovation." Journal of Transport Geography 22: 34-45. doi.org/10.1016/j.jtrangeo.2011.11.017

TACTRAN. 2010. “Tactran Freight Consolidation Feasibility Study”. Available at: http://www.tactran.gov.uk/documents/TactranFreightConsolidationDraftFeasibilityReport2804 10.pdf (Accessed 20 February 2018).

Van Duin, J. H. Ron., Hans Quak, and Jesús Muñuzuri. 2010. "New Challenges for Urban Consolidation Centres: A Case Study in The Hague." Procedia-Social and Behavioral Sciences 2(3): 6177-88. doi.org/10.1016/j.sbspro.2010.04.029

Van Duin, J. H Ron, Marijn Slabbekoorn, Lori Tavasszy, and Hans Quak. 2018. "Identifying Dominant Stakeholder Perspectives on Urban Freight Policies: A Q-Analysis on Urban Consolidation Centres in The Netherlands." Transport 33(4): 867-80. doi.org/10.3846/16484142.2017.1350996

Ville, Sandrine, Jesus Gonzalez-Feliu, and Laetitia Dablanc. 2013. "The Limits of Public Policy Intervention in Urban Logistics: Lessons from Vicenza (Italy)." European Planning Studies 21(10): 1528-41. doi.org/10.1080/09654313.2012.722954

Yang, Zhong Zhen, and Douglas Rome Moodie. 2011. "Locating Urban Logistics Terminals and Shopping Centres in a Chinese City." International Journal of Logistics Research and Applications 14(3): 165-77. doi.org/10.1080/13675567.2011.609159

Yin, Robert K. 2011. Applications of Case Study Research (Second Edition). London: Sage.

Yin, Robert K. 2014. Case Study Research and Applications: Design and Methods. London: Sage. 